\title{
MG-63 Cell Proliferation with Static or Dynamic Compressive Stimulation on an Auxetic PLGA Scaffold
}

\author{
Myeong Jin Kim, ${ }^{1}$ Hong Jin Choi, ${ }^{1}$ Jongman Cho, ${ }^{1}$ Jung Bok Lee, ${ }^{2}$ \\ Hak-Joon Sung, ${ }^{2}$ and Jeong Koo Kim ${ }^{1}$ \\ ${ }^{1}$ School of Biomedical Engineering, Inje University, Obang-Dong, Gimhae, Gyeongnam 621-749, Republic of Korea \\ ${ }^{2}$ Department of Biomedical Engineering, Vanderbilt University, Nashville, TN 37212, USA \\ Correspondence should be addressed to Jeong Koo Kim; jkkim@inje.ac.kr
}

Received 22 September 2016; Revised 5 December 2016; Accepted 22 December 2016; Published 15 January 2017

Academic Editor: Kevin Kang

Copyright (C) 2017 Myeong Jin Kim et al. This is an open access article distributed under the Creative Commons Attribution License, which permits unrestricted use, distribution, and reproduction in any medium, provided the original work is properly cited.

\begin{abstract}
The effect of dynamic compressive stimulation on MG-63 cell proliferation on an auxetic PLGA scaffold was investigated. The estimated Poisson ratio of the prepared auxetic scaffold specimens was approximately $(-) 0.07$, while the Poisson ratio estimated for conventional scaffold specimens was $(+) 0.12$ under $10 \%$ strain compression on average. Three stimulus groups were examined: control (no stimulation), static compression, and dynamic compression. In preparation for proliferation testing, cells were seeded at $2.2 \times 10^{5}$ cells $/ 80 \mu \mathrm{L}$ on each scaffold specimen. The average proliferation rates of the static and dynamic groups were higher than those of the control group: $13.4 \%$ and $25.5 \%$ higher at culture day $1,34.7 \%$ and $56.2 \%$ at culture day 3 , and $17.5 \%$ and $43.0 \%$ at culture day 5 , respectively. The static and dynamic group results at culture day 5 were significantly different $(p<0.01)$. Moreover, proliferation rate of the dynamic stimulation group was 1.22 times higher than that of the static group $(p<0.01)$. Conclusively, proliferation of osteoblast-like cells was enhanced through compressive stimulation, but the enhancement was maximal with dynamic compressive stimulation of auxetic scaffolds.
\end{abstract}

\section{Introduction}

A scaffold or three-dimensional structure can provide the support necessary for new cell growth by providing a porous structure, an adequate degradation rate, and an architectural structure that provide an appropriate shape for new bone and cartilage $[1,2]$. On that basis, many researchers have undertaken studies aimed at changing the support structure through chemical treatment, electric-physical stimuli, or varying the inner pore shapes of the scaffold [3].

Material's Poisson's ratio is defined as the lateral contraction strain divided by the longitudinal extension strain. In most materials, Poisson's ratio, usually denoted by $v$, is a positive value. Materials with negative Poisson's ratio (NPR) are called auxetic materials [4-7]. The first mechanical model of a structure exhibiting NPR was described by Almgren (1985) [8], and the first thermodynamic model of a system forming a phase with NPR, which means that the auxetic structure phase was built spontaneously by the model's molecules, was studied by performing computer simulations $[9,10]$. Auxetic stent applications have been reported by Gatt et al. (2014) [11] and Mizzi et al. (2014) [12]. A series of focus issues on auxetics has been published by Wojciechowski et al. (2016) [13]. Auxetic structural materials can exhibit enhanced and improved properties over conventional materials; for example, they can increase indentation resistance and provide good shock-absorptive properties $[6,7,14,15]$. Fabrication of auxetic structural scaffolds can be achieved by transforming the cell structure from a convex polyhedral shape to a concave or reentrant shape in which cell ribs protrude inward. Such structures have a characteristic inverted manner that is similar to that of a honeycomb [15-17]. A natural auxetic material that has been studied and predicted to have NPR is the load-bearing cancellous bone present in human shins. In tissue engineering, an auxetic scaffold exhibits concurrent axial and transverse expansion or contraction. It has been 
suggested that, compared to nonauxetic scaffolds, auxetic scaffolds would better integrate with native tissues and/or better promote clinical hard tissue regeneration [18, 19].

Mechanical stress has been recognized as a crucial factor in determining bone cell activity. The piezoelectric property of bone was first reported by Fukada and Yasuda in the late 1950s [20] and later Bassett and co-workers independently verified the theory [21]. Functional adaptation of bone was first introduced by Wolff as the "law of bone transformation" in the 1870 s. Bone modifies its structure by sensing mechanical stresses generated by dynamic loading and unloading cycles in vivo, which in turn generate the electricity that triggers bone remodeling activities as well as bone cell proliferation [22-27].

Biodegradable polymer scaffolds are widely used in tissue engineering, but there are few reports on auxetic biodegradable scaffolds $[28,29]$. In this study, an auxetic scaffold and its effectiveness on isotropic stress delivery to cells (static/dynamic) were investigated. The goal of the study was to achieve effective bone cell proliferation under various compressive stimulus (static/dynamic) conditions through an auxetic scaffold.

\section{Materials and Methods}

2.1. Scaffold Fabrication. Conventional three-dimensional scaffolds were fabricated by using a solvent casting/particulate salt leaching method. Biodegradable poly(D,L-lactideco-glycolide) (PLGA) was purchased from Lakeshore Biomaterials (Evonik, USA). The molar ratio of the lactide and glycolide was $50 / 50$ and the molecular weight was $79 \mathrm{kDa}$. The glass transition temperature was $46.9^{\circ} \mathrm{C}$. The polymer was dissolved in chloroform (Duksan Pure Chemicals, Korea) at a concentration of $25 \%(\mathrm{v} / \mathrm{w})$. Sodium chloride particulates in the $325-400 \mu \mathrm{m}$ range were mixed together to create a conventional scaffold. The polymer solution was poured into a prepared $15 \times 15 \times 15 \mathrm{~mm}$ mold for scaffold specimen fabrication and then dried at room temperature for $1 \mathrm{~d}$. After drying, the specimens were removed from the mold and washed with distilled water for $2 \mathrm{~d}$ in order to remove sodium chloride particles. Finally, the specimens were freeze-dried for $24 \mathrm{~h} \mathrm{[30].}$

Auxetic scaffold specimens were prepared by a volumetric restriction method. Materialization of specimens possessing Poisson's ratio was implemented by performing three-axial compression with heat treatment. Before applying 3-axial compression, the scaffold size was $20 \times 20 \times 20 \mathrm{~mm}$ and pore size was 500-600 $\mu \mathrm{m}$. After 3-axial compression with heat treatment, the scaffold was $15 \times 15 \times 15 \mathrm{~mm}$. Heat treatment $\left(60^{\circ} \mathrm{C}\right)$ was applied for $10 \mathrm{~min}$ while applying the 3 -axial compression [31]. The 3-axial compression ratio was $2.4: 1$.

To identify the shapes of the generated pores, the prepared scaffolds were observed by using a scanning electron microscope (SEM; 3-4300DSE, Hitachi, Tokyo, Japan).

2.2. Measurement of Poisson's Ratio. To determine scaffold specimen's Poisson's ratio, compressive loading was applied to the specimens by using a material testing system (MTS,

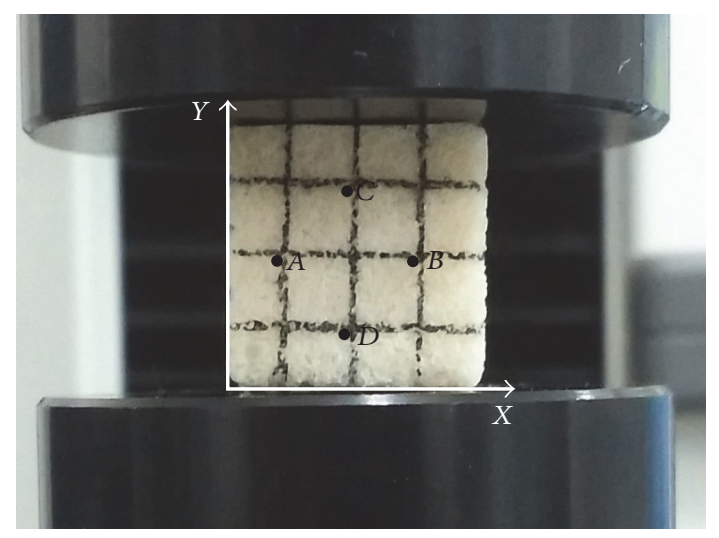

Figure 1: Initial (preloading) points $A-D$ on a representative specimen used to estimate Poisson's ratio of a scaffold.

Lloyd Instrument, UK). All specimens were marked on their surfaces as shown in Figure 1. Each specimen was measured over a 5\%-25\% range of compression strain [29]. Cross head speed of the MTS was $1 \mathrm{~mm} / \mathrm{min}$. Scaffold displacement at each $5 \%$ strain interval was captured by using a digital camera.

Poisson's ratio $(\nu)$ is expressed by the strain of the $x$-axis $\left(\varepsilon_{x}\right)$ against the strain of the $y$-axis $\left(\varepsilon_{y}\right)$. Points $A_{0}$ and $B_{0}$ were the initial, unloaded points on the $x$-axis of a specimen, whereas points $C_{0}$ and $D_{0}$ were the initial unloaded points on the specimen's $y$-axis. The positions of these points changed with compressive loading over the tested strain level range of $0 \%-25 \%$. Deformation of the scaffold at each of the $5 \%$ strain intervals was recorded by using a digital camera. Camera images were analyzed by using Microsoft Visio 2007. The $x$ axis and $y$-axis strains were obtained by determining distance changes for postloading points $A-B$ and $C-D$ by using the following equations [32]:

$$
\begin{gathered}
\varepsilon_{x}=\frac{|A-B|-\left|A_{0}-B_{0}\right|}{\left|A_{0}-B_{0}\right|}, \\
\varepsilon_{y}=\frac{|C-D|-\left|C_{0}-D_{0}\right|}{\left|C_{0}-D_{0}\right|}, \\
\nu=-\frac{\varepsilon_{x}}{\varepsilon_{y}},
\end{gathered}
$$

where $\varepsilon_{x}$ is strain of $x$-axis, $\varepsilon_{y}$ is strain of $y$-axis, $v$ is Poisson's ratio, $A_{0} \sim D_{0}$ is initial point (without loading), and $A \sim D$ is moved point (with loading).

2.3. Elasticity of Auxetic Scaffold Specimen. Measurement of the recovery rate of the scaffold was conducted with loading and unloading of the scaffold under $10 \%$ compressive strain for 1,5 , and $15 \mathrm{~min}$. The recovery position after unloading was measured after 1,5 , and $15 \mathrm{~min}$. The recovery rate was expressed as the ratio of the return position to the original position. 


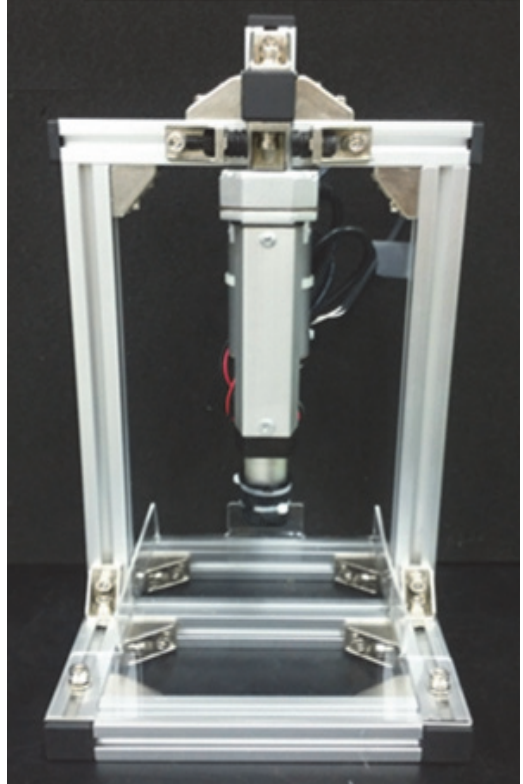

(a)

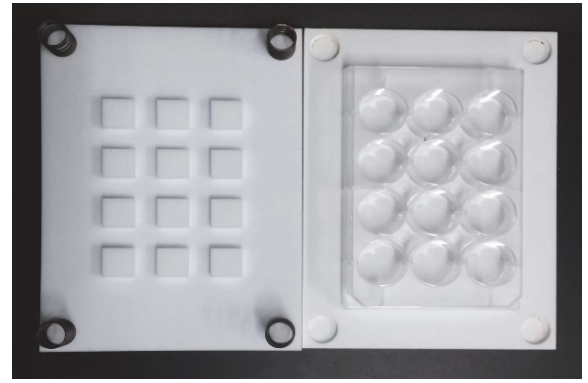

(b)

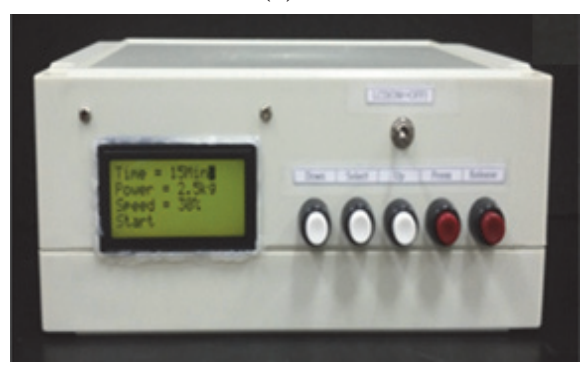

(c)

FIGURE 2: Compressive stimulation apparatus used during cell cultivation; (a) actuator device, (b) PTFE mold, and (c) control device to control stimulation cycle, load, and speed.

2.4. Cell Culture with Compressive Stimulation. The compressive stimulation apparatus was designed and prepared by using a Teflon mold and actuator (KDSJ002, NTREX, Korea) for cell cultivation under static or dynamic stimulation conditions (Figure 2(a)). Using this apparatus, cellular culture with mechanical stimulation was possible with as many as 12 specimens at the same time (Figure 2(b)). The apparatus permitted control over the number of cycles, loading intensities, and loading speeds (Figure 2(c)).

The MG-63 osteoblast-like cells used in this study were obtained from the Korean Cell Line Bank, Seoul, Korea. Cell culture medium was a minimum essential medium (DMEM, Gibco) with 10\% fetal bovine serum (FBS; Gibco) and $1 \%$ Penicillin-Streptomycin (P/S; Sigma) with culture in a humidified incubator with $5 \% \mathrm{CO}_{2}$ at $37^{\circ} \mathrm{C}$. All compressive stimulations (static and dynamic) were applied in the incubator. Before cell seeding, the prepared scaffolds were sterilized by immersion in $70 \%$ ethanol for $30 \mathrm{~min}$ followed by washing three times with phosphate buffer saline (PBS, Lonza) solution. To investigate the effect on cell proliferation of physical stimuli, three different groups were prepared. For all groups, prepared auxetic scaffolds were employed and the seeded cell density was $2.2 \times 10^{5}$ cells $/ 80 \mu \mathrm{L}$. The control group underwent no compressive stimulation. The static stimulation group underwent continuous loading with $10 \%$ strain compression. For dynamic stimulation, two load intervals were applied, $5 \mathrm{~min}$ and $15 \mathrm{~min}$, with on/off all the way. The applied loads were $19.6 \mathrm{~N}$ for $10 \%$ strain compression.

2.5. Estimation of Cellular Proliferation (CCK Assay). Cells were harvested at cultivation days 1,3 , and 5 . The cell proliferation rate was estimated by using a cell counting kit
(CCK-8, Dojindo Molecular Technologies, Maryland, USA). For proliferated cell harvest, specimens were twice washed with PBS solution. The CCK-8 solution (DMEM:CCK-8 ratio of $10: 1$ ) was added to each specimen-containing well. The mixed solution was then placed in a $\mathrm{CO}_{2}$ incubator for $3 \mathrm{~h}$ to react. Cell suspensions $(100 \mu \mathrm{L})$ were injected into a 96-well microplate. A $450 \mathrm{~nm}$ wavelength microplate reader (iMARK BIORAD, California) was used to measure cell proliferation in the scaffolds.

2.6. Statistical Analysis. Statistical analysis was conducted by using SPSS software. Data are presented as means \pm standard error. ANOVA was used to evaluate differences among the three groups. Student's $t$-test was used to evaluate differences between two groups. Significance level for differences was $p<0.05$.

\section{Results and Discussion}

Auxetic scaffolds were prepared successfully by using the volumetric restricted method. Figure 3 shows representative SEM images of the cross-sectional microstructural shape of pores in the PLGA scaffold. The shape of the pores in the conventional specimen was cubic and convex, as shown in Figure 3(a). In contrast, the prepared auxetic specimen had concave/reentrant shapes, as shown in Figure 3(b).

The concave/reentrant shape in the scaffold exhibits NPR when stretched or compressed. The results of this study indicate that the positive Poisson ratio of the conventional scaffold was $(+) 0.12 \pm 0.035$ under $10 \%$ strain compression, whereas the experimental specimen had NPR of (-) $0.07 \pm 0.036$ under $10 \%$ strain compression (Figure 4 ). The 


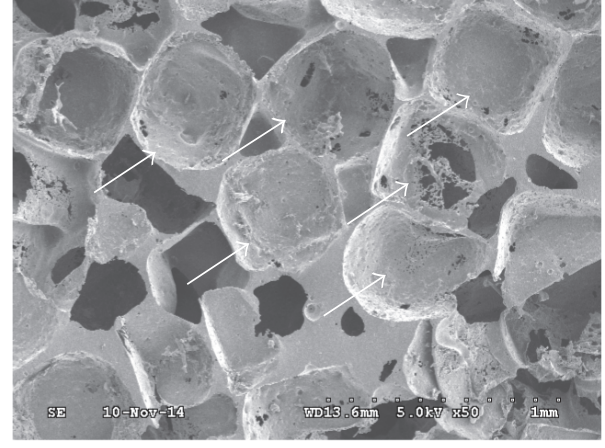

(a)

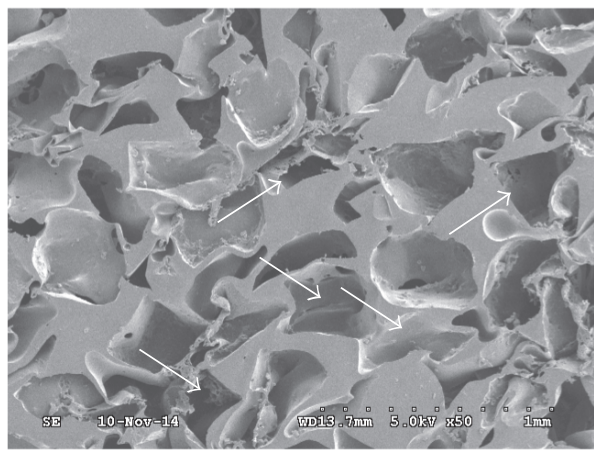

(b)

FIGURE 3: Representative SEM image of PLGA scaffolds of (a) a conventional scaffold specimen and (b) an auxetic scaffold specimen. The arrows indicate different pore structures (scale bar $=1 \mathrm{~mm}$ ).

maximum negative value of the Poisson's ratio of the experimental specimen was obtained at the $10 \%$ strain compression level.

The recovery rate of the auxetic scaffold specimens increased with increasing loading time (Figure 5). The highest recovery rate of the auxetic scaffolds subjected to $10 \%$ compressive strain was approximately $23.2 \%$ in the $15 \mathrm{~min}$ compression stimuli cycle.

The cell proliferation rate results obtained under dynamic stimulation are shown in Figure 6. Compared with the $5 \mathrm{~min}$ cycle interval, the 15 min cycle interval stimulated specimen showed 2.70 times, 1.36 times, and 1.16 times higher proliferation on culture days 1,3 , and 5 , respectively. The greatest intergroup difference was observed in the 1-day culture samples, and the relative difference narrowed with additional culture time. It is presumed that the polymer scaffold in a liquid medium should be loosened in strength due to the scaffold's viscoelastic property. Hence, transference of compressive stimulation through the scaffold could diminish with cell proliferation over time. The results indicate that a $15 \mathrm{~min}$ interval of dynamic stimulation permitted more effective cellular proliferation than that of a 5 min interval dynamic stimulation. Thus, we compared cellular proliferation in control (no stimulation), static compression stimulation, and 15 min interval dynamic compressive stimulation groups.

The cell proliferation rates in the control, static, and dynamic stimulation groups are presented in Figure 7. Cell

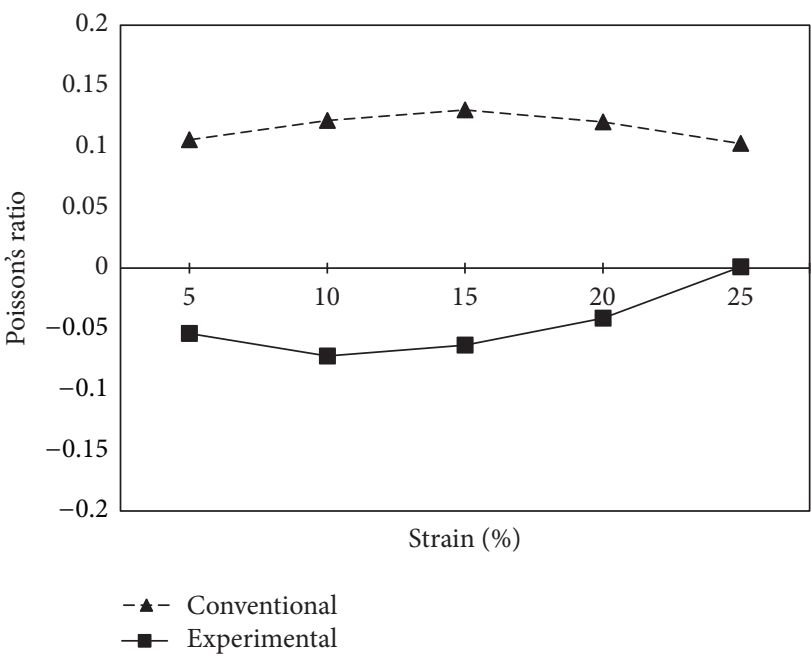

FIGURE 4: Poisson's ratio of PLGA scaffolds under 5\%-25\% strain compression conditions $(n=5)$.

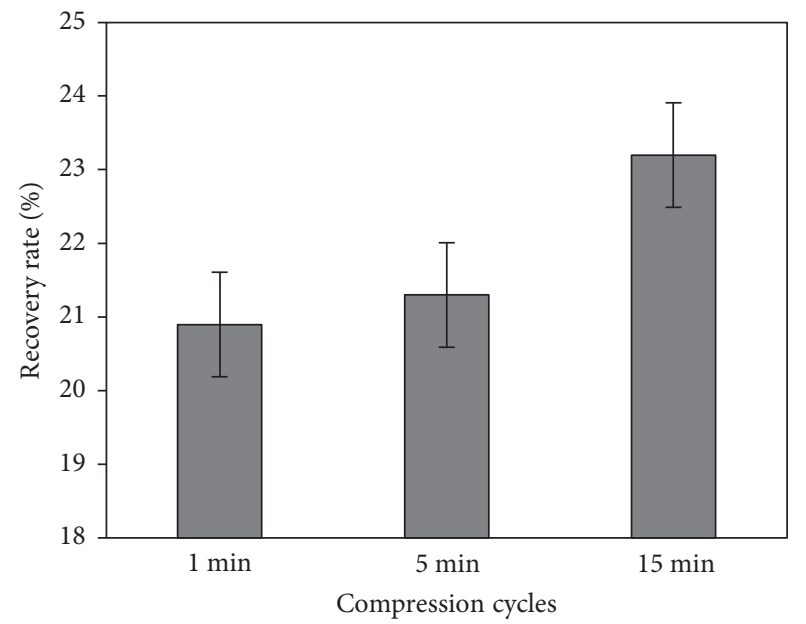

FIGURE 5: Recovery rate of PLGA scaffolds according to duration of compression stimuli cycles.

proliferation rate for the control group was far less than the rates in the stimulated groups. In particular, cell the proliferation rate was 1.43 times higher in the dynamic stimulation group than in the control group after $5 \mathrm{~d}$ of culture, a significant difference $(p<0.01)$. Comparison of the static and dynamic groups showed that the dynamic group had rates 1.11 times, 1.16 times, and 1.22 times higher than those in the static group on culture days 1,3 , and 5 , respectively.

\section{Conclusion}

The study investigated MG-63 osteoblast-like cell proliferation on auxetic scaffolds under static and dynamic compressive stimulation conditions. The convex porous PLGA scaffold was successfully transformed into a reentrant porous form that had special pore structures and NPR. Our previous study revealed that this structure could deliver a compressive 


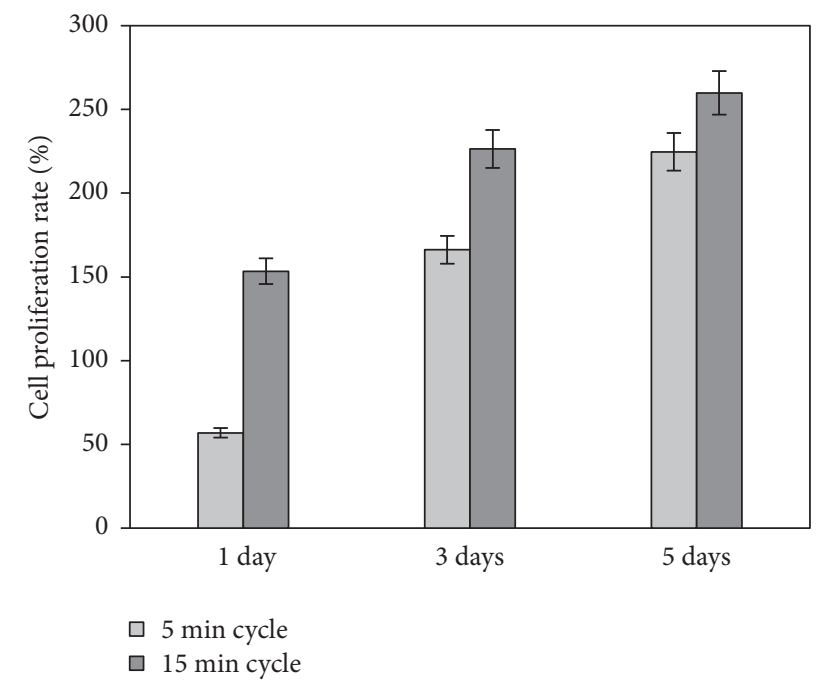

Figure 6: MG-63 cell proliferation rates in $5 \mathrm{~min}$ and $15 \mathrm{~min}$ dynamic stimulation groups.

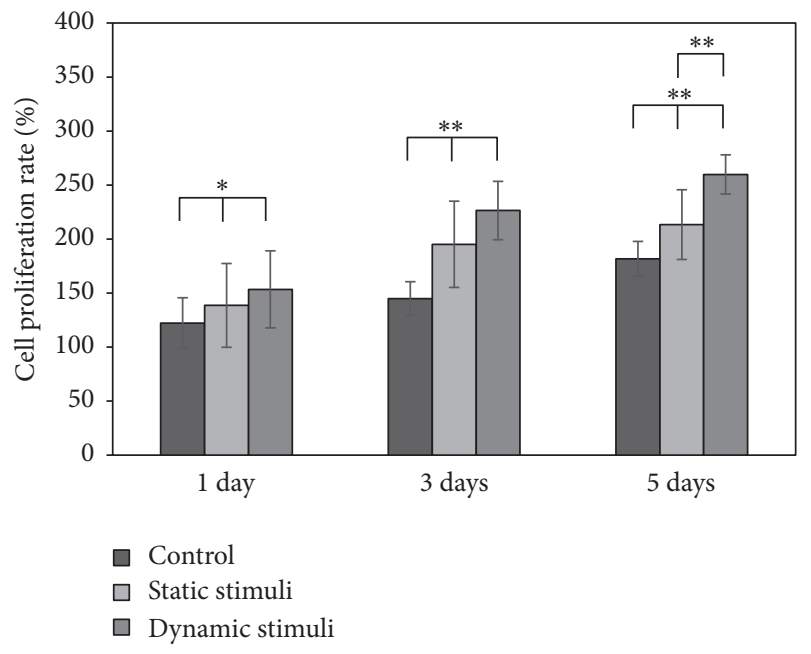

FIGURE 7: MG-63 cells proliferation rates on auxetic PLGA scaffolds in control (no compression), static stimuli, and dynamic stimuli groups under 15 min compression and after culture of 1,3 , and $5 \mathrm{~d}$. $\left(n=4,{ }^{*} p<0.05\right.$, and $\left.{ }^{* *} p<0.01\right)$.

load isotropically to cells in the scaffold, and it had an effect on cell proliferation $[33,34]$. In this study we investigated which type of compressive stimulation, that is, static or dynamic, could be more effective in bone cell proliferation. The results indicate that both static compressive stimulation and dynamic compressive stimulation are effective in increasing the cell proliferation rate. In both static and dynamic stimulation groups, the efficiency of stimulation delivery to the cells decreased with an increase in culture period.

Dynamic compressive stimulation was more effective than static stimulation on MG-63 cell proliferation. The inferred reason for that difference is that human bone is exposed to dynamic compression in normal life. Thus, osteoblast-like cells undergoing dynamic stimulation will exhibit a higher proliferation rate than that in cells undergoing static compressive stimulation. Further studies are necessary to address this suggestion.

\section{Competing Interests}

The authors declare no conflict of interests.

\section{Acknowledgments}

This work was supported by a grant from Research year of Inje University, 20150439.

\section{References}

[1] D. W. Hutmacher, "Scaffolds in tissue engineering bone and cartilage," Biomaterials, vol. 21, no. 24, pp. 2529-2543, 2000.

[2] Y. Hu, S. R. Winn, I. Krajbich, and J. O. Hollinger, "Porous polymer scaffolds surface-modified with arginine-glycine-aspartic acid enhance bone cell attachment and differentiation in vitro," Journal of Biomedical Materials Research-Part A, vol. 64, no. 3, pp. 583-590, 2003.

[3] S. I. Jeong, B.-S. Kim, S. W. Kang et al., "In vivo biocompatibilty and degradation behavior of elastic poly(L-lactide-co- $\varepsilon$ caprolactone) scaffolds," Biomaterials, vol. 25, no. 28, pp. 59395946, 2004.

[4] R. S. Lakes, "Foam structures with a negative Poisson's ratio," Science, vol. 235, no. 4792, pp. 1038-1040, 1987.

[5] K. E. Evans, "Auxetic polymers: a new range of materials," Endeavour, vol. 15, no. 4, pp. 170-174, 1991.

[6] A. Díaz Lantada, E. C. Mayola, M. C. Huerta Gómez de Merodio, A. Muslija, J. P. García Ruíz, and H. Alarcón Iniesta, "Smart microsystems for active cell culture, growth and gene expression toward relevant tissues," in Microsystems for Enhanced Control of Cell Behavior, vol. 18 of Studies in Mechanobiology, Tissue Engineering and Biomaterials, chapter 14, pp. 227-247, Springer International, Cham, Switzerland, 2016.

[7] L. Teik-Cheng, Auxetic Materials and Structures, Springer, Berlin, Germany, 2015.

[8] R. F. Almgren, "An isotropic three-dimensional structure with Poisson's ratio =-1," Journal of Elasticity, vol. 15, pp. 427-430, 1985.

[9] K. W. Wojciechowski, "Constant thermodynamic tension monte carlo studies of elastic properties of a two-dimensional system of hard cyclic hexamers," Molecular Physics, vol. 61, no. 5, pp. 1247-1258, 1987.

[10] K. V. Tretiakov and K. W. Wojciechowski, "Poisson's ratio of the fcc hard sphere crystal at high densities," Journal of Chemical Physics, vol. 123, no. 7, Article ID 074509, 2005.

[11] R. Gatt, R. Caruana-Gauci, D. Attard et al., "On the properties of real finite-sized planar and tubular stent-like auxetic structures," Physica Status Solidi (B) Basic Research, vol. 251, no. 2, pp. 321327, 2014

[12] L. Mizzi, D. Attard, A. Casha, J. N. Grima, and R. Gatt, "On the suitability of hexagonal honeycombs as stent geometries," Physica Status Solidi (B), vol. 251, no. 2, pp. 328-337, 2014.

[13] K. W. Wojciechowski, F. Scarpa, J. N. Grima, and A. Alderson, "Auxetics and other systems of 'negative' characteristics," Physica Status Solidi (b) Basic Research, vol. 253, no. 7, pp. 1241-1242, 2016. 
[14] R. S. Lakes, "Design considerations for materials with negative Poisson's ratios," Journal of Mechanical Design, Transactions Of the ASME, vol. 115, no. 4, pp. 696-700, 1993.

[15] B. Brandel and R. S. Lakes, "Negative Poisson's ratio polyethylene foams," Journal of Materials Science, vol. 36, no. 24, pp. 5885-5893, 2001.

[16] R. S. Lakes and R. Witt, "Making and characterizing negative Poisson's ratio materials," International Journal of Mechanical Engineering Education, vol. 30, no. 1, pp. 50-58, 2002.

[17] J. B. Choi and R. S. Lakes, "Analysis of elastic modulus of conventional foams and of re-entrant foam materials with a negative Poisson's ratio," International Journal of Mechanical Sciences, vol. 37, no. 1, pp. 51-59, 1995.

[18] S. K. Bhullar, A. M. Hewage, A. Alderson, K. Alderson, and M. B. Jun, "Influence of negative Poisson's ratio on stent applications," Advances in Materials, vol. 2, no. 3, pp. 42-47, 2013.

[19] D. Y. Fozdar, P. Soman, J. W. Lee, L.-H. Han, and S. Chen, "Three-dimensional polymer constructs exhibiting a tunable negative Poisson's ratio," Advanced Functional Materials, vol. 21, no. 14 , pp. 2712-2720, 2011.

[20] E. Fukada and I. Yasuda, "On the piezoelectric effect of bone," Journal of the Physical Society of Japan, vol. 12, no. 10, pp. 11581162, 1957.

[21] C. A. L. Bassett, H. R. Chokshi, E. Hernandez et al., "Electrical properties of bone and cartilage," Grune and Stratton, pp. 427441, 1979.

[22] R. M. H. Rumney, A. Sunters, G. C. Reilly, and A. Gartland, "Application of multiple forms of mechanical loading to human osteoblasts reveals increased ATP release in response to fluid flow in $3 \mathrm{D}$ cultures and differential regulation of immediate early genes," Journal of Biomechanics, vol. 45, no. 3, pp. 549-554, 2012.

[23] A. Kadow-Romacker, J. E. Hoffmann, G. Duda, B. Wildemann, and G. Schmidmaier, "Effect of mechanical stimulation on osteoblast- and osteoclast-like cells in vitro," Cells Tissues Organs, vol. 190, no. 2, pp. 61-68, 2009.

[24] T. P. Appelman, J. Mizrahi, J. H. Elisseeff, and D. Seliktar, "The influence of biological motifs and dynamic mechanical stimulation in hydrogel scaffold systems on the phenotype of chondrocytes," Biomaterials, vol. 32, no. 6, pp. 1508-1516, 2011.

[25] S. D. Waldman, C. G. Spiteri, M. D. Grynpas, R. M. Pilliar, and R. A. Kandel, "Long-term intermittent compressive stimulation improves the composition and mechanical properties of tissueengineered cartilage," Tissue Engineering, vol. 10, no. 9-10, pp. 1323-1331, 2004.

[26] C.-Y. C. Huang, K. L. Hagar, L. E. Frost, Y. Sun, and H. S. Cheung, "Effects of cyclic compressive loading on chondrogenesis of rabbit bone-marrow derived mesenchymal stem cells," Stem Cells, vol. 22, no. 3, pp. 313-323, 2004.

[27] D. Kaspar, W. Seidl, C. Neidlinger-Wilke, A. Beck, L. Claes, and A. Ignatius, "Proliferation of human-derived osteoblast-like cells depends on the cycle number and frequency of uniaxial strain," Journal of Biomechanics, vol. 35, no. 7, pp. 873-880, 2002.

[28] Y. J. Park and J. K. Kim, “The effect of negative Poisson's ratio polyurethane scaffolds for articular cartilage tissue engineering applications," Advances in Materials Science and Engineering, vol. 2013, Article ID 853289, 5 pages, 2013.

[29] Q. Hou, D. W. Grijpma, and J. Feijen, "Porous polymeric structures for tissue engineering prepared by a coagulation, compression moulding and salt leaching technique," Biomaterials, vol. 24, no. 11, pp. 1937-1947, 2003.
[30] A. A. Pozniak, J. Smardzewski, and K. W. Wojciechowski, "Computer simulations of auxetic foams in two dimensions," Smart Materials and Structures, vol. 22, no. 8, Article ID 084009, 2013.

[31] R. Gatt, D. Attard, E. Manicaro, E. Chetcuti, and J. N. Grima, "On the effect of heat and solvent exposure on the microstructure properties of auxetic foams: A Preliminary Study," Physica Status Solidi (B) Basic Research, vol. 248, no. 1, pp. 39-44, 2011.

[32] R. D. Widdle Jr., A. K. Bajaj, and P. Davies, "Measurement of the Poisson's ratio of flexible polyurethane foam and its influence on a uniaxial compression model," International Journal of Engineering Science, vol. 46, no. 1, pp. 31-49, 2008.

[33] Y. J. Park, MG-63 osteoblastic-like cell proliferation on auxetic PLGA scaffold with mechanical stimulation for bone tissue engineering [M.S. thesis], Inje University, Gimhae, South Korea, 2014.

[34] H. J. Choi, J. J. Lee, Y. J. Park et al., "MG-63 osteoblast-like cell proliferation on auxetic PLGA scaffold with mechanical stimulation for bone tissue regeneration," Biomaterials Research, vol. 20, article 33, 2016. 

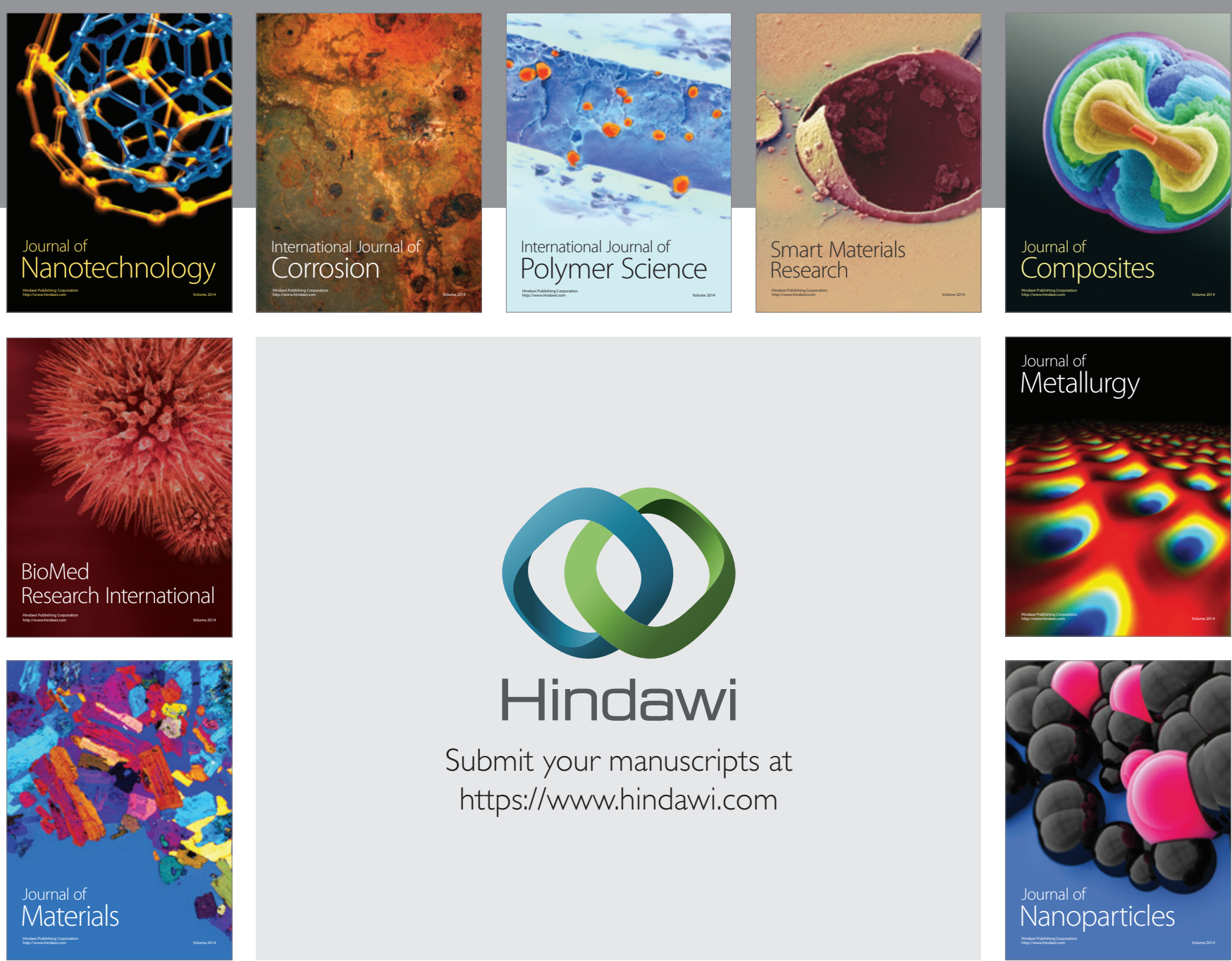

\section{Hindawi}

Submit your manuscripts at

https://www.hindawi.com

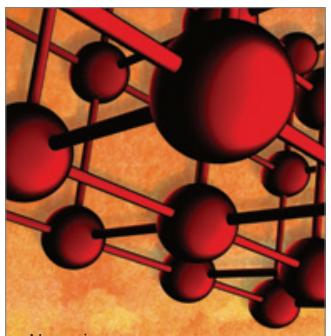

Materials Science and Engineering
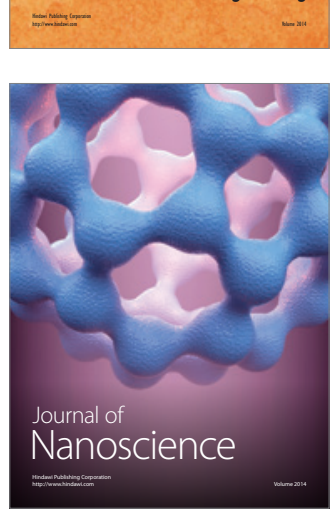
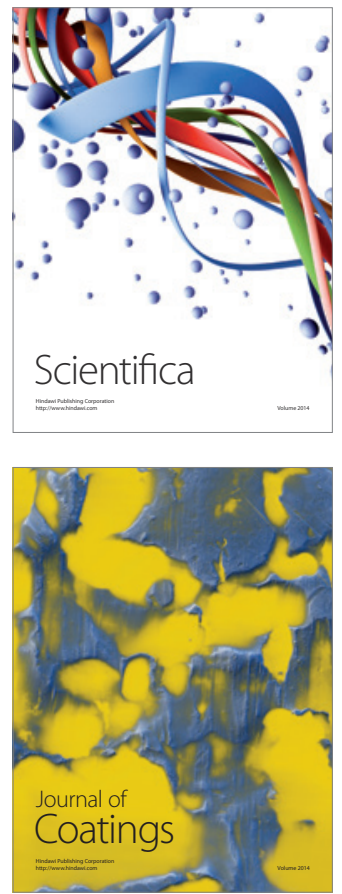
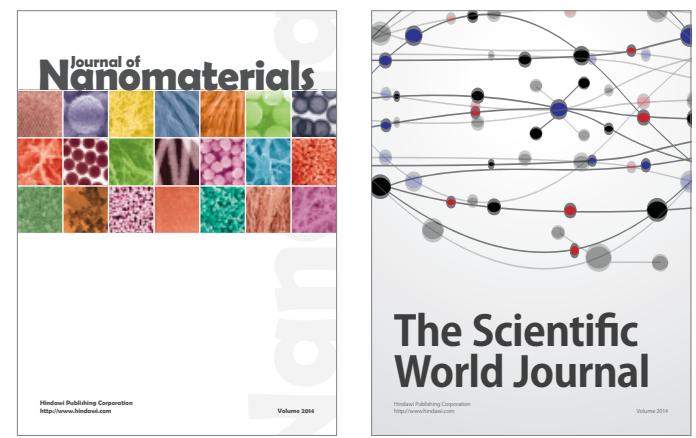

The Scientific World Journal
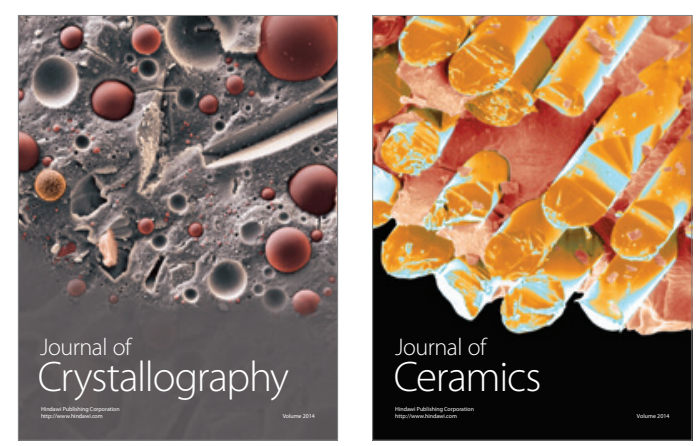
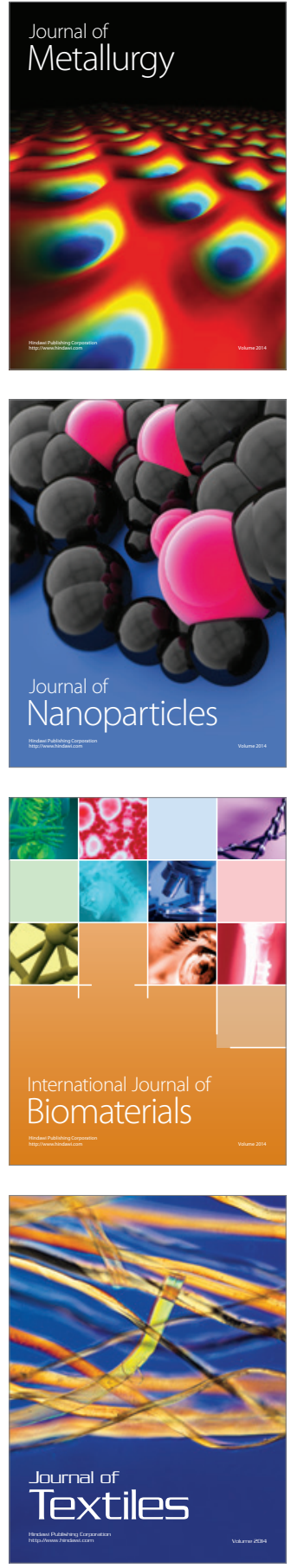